\section{Managing a Multiauthor Research Project in Comparative Politics}

\author{
Kent Weaver, Brookings Institution \\ T. J. Pempel, University of Wisconsin-Madison \\ Nancy N. Davidson, Brookings Institution \\ Sidney Verba, Harvard University \\ Keith G. Banting, Queen's University, Kingston, Ontario
}

consuming to produce. If you are planning to compile such a book, you should find out first if anyone wants to publish it and what their requirements are. The most important thing you can do to enhance your project's attractiveness and value is to shape the disparate pieces into a well-focused whole.

Another potential downside to edited volumes is that project managers are unlikely to get professional credit for the volume commensurate with the work they put into it. The profession values single-authored work rather than administrative expertise, and you will get no credit for the ideas you pass on to collaborators in shaping their chapters. As T. J. Pempel wittily noted at our panel, no matter how much work you put into shaping your own contributions and those of other authors into a coherent whole, the book reviews for edited volumes almost invariably begin, "Here is another edited volume, highly uneven in quality, that would have been far better if it had included my favorite country, my favorite topic, or me."

All of these problems escalate with jointly authored volumes or multivolume series. Jointly authored volumes have the greatest need for uniformity in theory, purpose, and style. Even authors who see eye-toeye at the outset are likely to find themselves clashing on details as a project unfolds. The risks rise exponentially with the number of coauthors.

Multivolume projects pose a different set of challenges. The authors of individual volumes will feel, understandably, that the book is their responsibility and they should march to their own drummer rather than to yours. Maintaining coherence through a series of volumes, while 
allowing autonomy and creativity to the individual authors you have selected, is likely to involve a massive effort in human relations over a halfdecade or more. Multivolume series also pose a difficult chicken-or-egg problem in marketing: it is difficult to line up authors when you don't have a contract for the series, and you can't get a series commitment from a publisher without hard copy and commitments from authors.

Whatever your choice of scope and format, it is essential that the research design be compatible with the limits of the capacity of your proposed format: if you want to focus on several categories of policies or countries and have several cases in each category, for example, you will rapidly find yourself at the outer limits of what can reasonably fit into a single volume. A volume is likely to seem too bulky if it has more than five or six case studies. But if you have a complex causal framework, weighing the effects of two or three independent variables, this may not be enough to make a very persuasive argument.

\section{Uniformity or Diversity in Research Design?}

Another choice project managers must make early is whether contributors should follow closely a single research methodology and format for presentation or have freer rein. "Uniformalists" argue that tools like a common survey instrument, methodology for selecting interviewees, and conceptual framework allow more rigorous comparisons to be made across cases. "By-us"efs, on the other hand, argue that since conditions differ across countries, common instruments and methodologies are likely to be appropriate only for the country where the instrument designers live and work; research design should be handled "by us" since it's different in our country. Of course, both approaches have value; the two positions are extremes, and there is room for compromise in the middle. Which pole you lean toward should depend in large measure on the research question you are addressing.

\section{Parsimony or Redundancy in Case Selection?}

A related trade-off concerns the degree of redundancy you include in your research design. Minimizing the number of cases reduces the burden of research, research costs, and the physical heft of the resulting product. But there is also a strong case for redundancy. If your project includes a number of case studies with a single dichotomous independent or dependent variable, for example, having more than one case with each of these attributes may save the project from self-destructing if one of the case-study authors does not come through with an acceptable

\section{The most important thing} you can do to enhance

your project's

attractiveness and value is

to shape the disparate pieces into a well-focused whole.

piece of work. You don't want to end up with no variance to explain or to explain with. Moreover, having two or more case studies with slightly conflicting results may in fact open up new theoretical insights that would have been missed by a more tightly structured project.

\section{One Head or Several?}

Managing a big multiauthor research project sounds like a lot of work, and it is. An obvious solution is to split up the load among several chiefs. This brings with it several problems, however, that should be familiar to any political scientist who has studied regulatory commissions, legislatures, or courts. The heads may disagree on substantive or procedural issues or both, convey conflicting messages to collaborators about how to proceed, and give the final project a schizoid appearancea sure ticket to unpublishability. Multiple project managers may also shirk the unpleasant but most essen- tial work (for example, helping collaborators who have turned in particularly weak drafts or dealing with publishers' requests for accurate documentation). And they may have personality and ego clashes, believing (almost inevitably) that their coheads are doing too little of the work and getting too much of the credit.

This is not to say that such arrangements cannot work, but it helps if prospective project managers know, like, and trust one another at least at the beginning of the project and are certain that they share a common vision of how the project should proceed. Foreordained decision rules and other nifty political science tricks aren't much help in resolving conflicts among small groups of two to four project managers.

\section{Packaging a Proposal}

Somewhere along the way in developing a collaborative research project, you will need money to hold conferences, pay research costs and honoraria, etc. There are no grand principles on how to attract funding. But, at the risk of undermining our future competitive advantage in fund-raising, we can suggest a few tips. First, recruiting big names can give a project more legitimacy with both funders and publishers. Second, you should be sensitive to the zeitgeist: buzzwords that reflect "new" trends in the discipline or public policy concerns are more likely to succeed in raising money from universities and foundations than those that seem to propose simply a rehash of old themes. Finally, projects look a lot better if they show real diversity among the contributors-in age, gender, ethnicity, nationality, and university affiliation-than if it looks as though a lot of 55-year-old white males at Our Lady of the Tundra University in Nome, Alaska, are going to schmooze over coffee at the faculty club.

\section{Recruiting Collaborators}

Your major opportunity to exercise quality control in multiauthor research projects comes at the stage of recruiting collaborators. It is critical to recruit people with a 
strong track record of producing high-quality research and with strong internalized standards of quality control. Avoid prima donnas who have never had an unpublished thought and do not think that any improvement could possibly be made in their first drafts. Avoid as well colleagues who may be brilliant conference participants but have trouble getting their insights onto the printed page.

Getting a high level of commitment to quality control is likely to be particularly difficult with contributors to edited volumes because the profession tends to reward this sort of publication less highly than singleauthored volumes or articles in refereed journals. Thus, while project managers may seek perfection because they anticipate additional rewards from producing a volume of uniformly high quality, contributors are likely to satisfice on quality so that they can move on to their next project, which may offer greater potential career rewards.

Preexisting substantive expertise is another important attribute to look for in collaborators. Given people's busy schedules and research agendas, it is unrealistic to expect that they will produce high-quality essays in a timely fashion if they also have to master huge literatures before they can begin. Once you get into crossnational studies-especially comparisons involving the United States and one or more other countries-the pool of potential collaborators becomes very small indeed.

Substantive expertise does not necessarily mean relying on senior scholars, however. Indeed, senior and junior researchers each offer distinctive risks and opportunities as collaborators. Junior scholars tend to be more malleable, more punctual, and closer to the data. Senior scholars may have a better overview. (In the immortal words of T. J. Pempel, junior colleagues engage in fly-fishing, trying delicately to land a single healthy trout; senior colleagues seem more prone to drop dynamite in the water and see what floats to the surface.)

Senior colleagues also add visibility in the profession, which helps to sell books and may attract other desired collaborators ("Hell, if Fred and Wilma think this is worthwhile, I'd better not miss it, even if the conference is in Iowa City"), and they may be able to make a greater level of commitment since they don't have to worry about getting tenure. But senior people also have a distressing tendency to assume administrative positions that cause research and writing time to disappear unexpectedly, forcing the project manager to find a replacement author or a new coauthor for that part of the project, or simply to drop that piece altogether.

... projects look a lot better if they show real diversity among the contributors-in age, gender, ethnicity, nationality, and university affiliation-than if it looks as though a lot of 55-year-old white males at Our Lady of the Tundra University in Nome, Alaska, are going to schmooze over coffee at the faculty club.

Theoretical flexibility is another desirable attribute in a collaborator. Unfortunately, there is often a tradeoff between this attribute and substantive expertise. People who have already done a lot of work in an area may have developed a big career stake in a particular set of explanatory variables: if they have already published a book saying that cultural differences are the major explanation for differences in welfare state size, for example, they may not be open to explanations that focus on the role of experts or political parties, since this contradicts their previous work.

The more senior the scholars, the larger the body of work that they may feel they have to defend. There is no sure way to pre-judge this attribute: you just need to feel out the potential collaborators to get a sense of their flexibility before you sign them up. If you get the sense that a potential collaborator is more interested in settling old academic scores than pursuing your research agenda, find someone else.

Project managers should also make sure that participation in their project flows out of each potential collaborator's current research agenda. Just because a scholar published work in a field or in a policy area five years ago does not mean that he or she is currently doing so; if project managers lean on old friends to join in a project when it no longer fits their agenda, they are likely to find that competing projects grab first place on the collaborators' lists of priorities. The ultimate result is likely to be a delayed, substandard product and frayed friendships. You should also make it clear at the outset if you want authors to do original research rather than simply rehashing their latest book or article in their contribution to a collective volume.

Another important recruitment principle is that the project managers should avoid recruiting collaborators who are also their superiors in a hierarchical institutional relationship. The reason is simple: project managers must be reasonably unconstrained in exercising quality control; this is difficult to do if the project managers are afraid to jettison a collaborator's contribution if the final draft isn't up to snuff or simply doesn't fit into the project. Avoid any collaborator whom you cannot afford to offend (e.g., your dean or department chair).

Project managers also have to make choices in choosing collaborators-and in framing a projectregarding the locale and nationality of contributors. Most of the problems endemic to all multiauthor projects are multiplied in comparative projects involving authors from a number of countries. The rapid proliferation of facsimile machines and electronic mail has made it easier to manage some aspects of international collaborations quickly and inexpensively, notably the editing of manuscripts. But this technology is not universally available, especially in some developing countries. Moreover, there is no substitute for faceto-face interactions in developing 
commitment to a shared agenda at the early stages of a project and for exchanging ideas as a project evolves. Having a far-flung group of authors can make this extremely expensive.

Other trade-offs may also arise with multinational authorship. Fullfledged partnership with scholars from the countries you are studying can give your project additional depth of knowledge about those countries and additional credibility. When Sidney Verba and Gabriel Almond were doing the research for The Civic Culture, for example, they hired researchers in other countries to gather data, and then they wrote it up. This worked well at the time, but you can't and shouldn't do it today. The United States is no longer an intellectual hegemon with a nearmonopoly on political science expertise.

If you rely heavily on foreign collaborators who are not native English speakers, you should find out before making commitments whether potential participants are truly fluent in English. If not, you may want to build in some time and money for translation, rather than try (with great effort) to improve their poor English writing. This is the point at which you might have to ask whether you want a Hungarian or an American expert on Hungary.

You should also bear in mind that styles of scholarship and writing differ among cultures. Some give more importance to evidence and documentation while others are more informal or essay-like. AngloAmericans tend to be obsessed with causation, while Germans like creating typologies. If you want a uniform style and theoretical orientation, choose your authors accordingly.

Dealing with authors from several countries can also complicate scheduling for your project. Remember that there will be many different holidays, vacation times, or sabbaticals, and you will have to be able to reach these people and get responses from them for many months after they think they have discharged their responsibility by simply turning in their papers.

Perhaps the most important thing to keep in mind when recruiting collaborators, however, is that in all multiauthor projects, it is at least as important for a contributor to be reliable and punctual (and to write well) as to be a great scholar. If you know that a scholar has had a lot of problems in the past meeting deadlines, look for someone else who can do the job for you. All it takes to bring a project to a crashing halt is for one contributor to be uncooperative or late. One of the most frustrating aspects of a collaborative project is the danger of losing highquality work from on-time contributors who seek to bail out and publish their pieces elsewhere because of delays caused by undelivered or potentially weak contributions from latecomers. You can guard against this by postponing most or all of the

\section{Project managers should also make sure that participation in their project flows out of each potential collaborator's current research agenda.}

honorarium until an author has provided all changes and documentation you want.

Finally, project managers should remember when recruiting collaborators that money talks, but not too loudly: substantial honoraria may have the perverse effect of enticing collaborators to the project who don't have any commitment to the managers' conceptual or methodological agenda.

\section{Setting the Agenda}

Even if project manager(s) have decided to allow substantial diversity in research design and presentation format in collaborative projects, it is important to get all of the collaborators on compatible intellectual wavelengths before they begin their own writing. The best way for managers to set the agenda is to have a very detailed draft of an introductory chapter or theme essay ready to show potential collaborators before they are signed on.

As the manager of the project, you also should convey to your collaborators your idea of who the audience is (generalists or specialists, Americans or foreigners), what topics not to cover (so as to avoid too much overlap), the approximate length of their contributions, and how technical or heavily documented you want them to be. In the case of parallel contributions (for example, case studies around a common theme), a general outline of the expected contribution can be helpful, showing authors what topics must be covered and what relationships must be addressed.

Another desirable-but expensive - principle is to get the collaborators on the project together to exchange ideas as frequently as possible. This principle should be taken into account when applying for initial funding for the project from university or foundation sources: market it as an ongoing research seminar. Two meetings of all participants are the absolute minimum: one near the beginning of the project, when project managers have a first draft of their introduction or theme essay and the other collaborators have outlines of their contributions, and one after the project managers have redrafted their theme essay or chapter and other collaborators have written first drafts. But two or three additional meetings are extremely helpful in getting more continuity and synchronization between parts of the project. They may also be helpful in setting deadlines to force the production of output on paper.

What you want to avoid at all costs is having to harangue contributors at the very end of the process to address common themes or use a previously agreed upon common format-or even worse, to have the project managers rewrite the introductions and conclusions of other authors' contributions to add a thin (and false) veneer of commonality. Some slippage from the central agenda is nevertheless inevitable, especially in multivolume projects where individual collaborators are responsible for writing entire volumes.

Project managers should also be aware that there are risks associated with a clear, pre-set agenda, however: it may blind you to the exis- 
tence or importance of critical phenomena that do not fit your framework. Alternatively, you may discover in your fieldwork that the important causal forces are somewhat different than you originally thought. In the latter case, you must choose between staying with an inadequate framework or trying to get a number of collaborators to all change course simultaneously in the same direction.

In working on Do Institutions Matter?, for example, editors Kent Weaver and Bert Rockman decided, after they had written two drafts of the introduction and their collaborators had completed first drafts of their papers, that their institutional framework should be broadened to incorporate additional variables. This meant not only a lot of additional work on their part, but also coaxing additional work out of the collaborators, who were understandably inclined to see their work as almost completed. Given that social scientists tend to be more akin to a herd of unruly cattle than to the Thunderbirds or the Blue Angels, sharp midcourse changes in direction are unlikely to be executed precisely, and they may cause a project to crash and burn.

\section{Dealing with Problem Collaborators}

No matter how careful you are in recruiting collaborators, it is almost inevitable that one or more will disappoint you in terms of the timeliness, quality, or intellectual fit of their output. Thus, the project manager(s) may be faced with a choice between writing off a bad intellectual investment or working with the outlying collaborators to make the contribution acceptable. How this dilemma should be resolved depends upon a number of factors, including the centrality of the problem contribution to the project (a tangential case is a lot easier to chuck than one critical to your argument), the personality and time schedule of the project managers (managers with ample time and cooperative rather than conflictual personal styles are most likely to try to work with problem chapters), and just how close to salvageable the contribution is.
If worse comes to worst, the modern technology of word processors makes it feasible (although hardly pleasant) for a project manager to rewrite (and rewrite again) parts of a problem contribution, but this is likely to create big tensions with the collaborators. What is clear, however, is that it doesn't pay to delay these decisions: the farther along you go, and the greater the author's investment of time in the project, the harder it is to say you aren't going to include his or her work in the final product.

\section{Dealing with the Publisher}

Dealing with a publisher involves trade-offs, too. With edited volumes, for example, you may have to decide

. . . in all multiauthor

projects, it is at least

as important for a

contributor to be reliable

and punctual (and to write

well) as to be a great

scholar.

between getting every piece into a

volume published by a marginal press or imposing tougher standards that attract a better press but alienate collaborators whose contributions are dropped. The same trade-off between additional work and publisher quality may come into play with jointly authored volumes; the problem here is likely to arise if some authors prefer to satisfice on press quality while others are maximizers. In this situation, the satisficers may feel justified in shirking the extra work needed to bring the volume up to quality-press standards.

You should also be aware that as project manager you will probably be the "point person" in all dealings with the eventual publisher of your project. The publisher will expect you to convey to the participants ahead of time the guidelines for them to follow (including what footnote style or computer format to use, if the publisher has a preference). You will have to do the preliminary sub- stantive editing before the manuscript goes to the publisher, and you may find that you have to do a lot of the work you had hoped the publisher would do, such as coordinating the transmittal of copyedited manuscripts and proofs, making sure everyone is meeting deadlines, and perhaps even producing the final camera-ready copy, complete with tables and figures.

In short, collaborative research projects can be a tremendous intellectual experience, but do not delude yourself into thinking that managing a multiauthor research project is an easy way to get a book to your credit. It is not easy, and the amount of credit that you will get is uncertain. Scholars who do not yet have tenure should be particularly wary of taking on a project manager role. The risks that a project will crash and burn are too high for someone whose tenure prospects depend on getting out a lot of publications in a specified time. Scholars are also likely to find that the ratio of credit received to effort made is low when the tenure review comes around. They may also find that they lack the clout to get senior colleagues to bend to the project agenda. And if project management duties are shared with a senior colleague, the young scholar may find that most of the credit accrues to the latter, regardless of how the work was divided.

The coauthors of this brief essay found collaboration on this miniproject to be quite easy for several reasons. The stakes were relatively low, because the credit to be fought over for an article in $P S$ is less than for one in $A P S R$, and most of the cogitation costs had already been sunk in preparing for the panel. The convenor of the panel provided the public good of organizing, circulating, and rewriting drafts. We have nonetheless collectively vowed to turn off E-mail, fax, and telephone in order to seclude ourselves with our obviously much-easier-to-manage, single-authored next projects. 


\begin{abstract}
About the Authors
Kent Weaver is a senior fellow in the governmental studies program at the Brookings Institution. T. J. Pempel is Glenn B. and Cleone Orr Hawkins Professor of Political Science at the University of WisconsinMadison. Nancy N. Davidson is acquisitions editor at the Brookings Institution. Sidney Verba is Carl H. Pforzheimer University Professor and director of the University Library at Harvard University. Keith G. Banting is director of the School of Policy Studies at Queen's University in Kingston, Ontario. Order of authorship was decided by a weighted index of time spent preparing the article and number of humorous one-liners used.
\end{abstract}

\section{Windows Statistics Packages}

\section{Carl Grafton and Anne Permaloff, Auburn University at Montgomery}

The first article in this $P S$ series appeared a decade ago and covered the first generation of microcomputer statistics packages. ${ }^{1}$ They were useful tools that performed many of the tasks that previously could only be managed on mainframe or minicomputers. Their memory requirements were $48 \mathrm{~K}$ or $64 \mathrm{~K}$, silicon pocket change by today's standards.

Our second and third PS statistics package articles appeared in $1988 .{ }^{2}$ They covered programs that represented enormous improvements over their predecessors. They were faster, offered a far greater variety of data manipulation and statistical techniques, and several provided graphics output that was unavailable in earlier products. These second generation programs also required more powerful hardware. Entirely new machines were needed; memory requirements were an order of magnitude greater (instead of 64K, 640K); and a hard disk was a near necessity.

All of the second-generation statistics packages were text-oriented DOS programs (except for a few that ran on the Macintosh), although some moved into the graphics mode when displaying plots. The second-generation programs were later improved with two or sometimes three new versions. These changes, such as the addition of menus to SYSTAT and improved data-handling capacity for STATGRAPHICS, were often welcome, but most of these programs retained their basic personalities.

In the last few months a third generation of statistics packages has been introduced. The new programs require Microsoft Windows 3.0 or 3.1. Once more, memory requirements have increased by an order of magnitude so that 4-8 megabytes are required, and new platforms are necessary. Many machines that would run a second-generation program without difficulty simply cannot be used with Windows. Windows demands more RAM, more hard disk space, a faster hard disk, faster clock speed, and graphics of higher resolution. The cost of such equipment has plummeted, but given especially severe budget constraints that plague higher education nearly everywhere, even these low prices may be too high for institutional or individual purchase.

\section{The Distinguishing Features of Windows Statistics Packages}

A program is not necessarily better because it has been ported to Windows. In addition to greater hardware demands and consequent costs, a Windows program may be slower than its DOS counterpart, although we have observed two startling exceptions to this normally valid rule. ${ }^{3} \mathrm{~A}$ Windows program may have on-screen help capabilities that are not as good as its DOS counterpart, and its menu structure may not be any easier to use.

Fundamentally, what distinguishes the better Windows statistics packages from DOS programs is greater ease of use. It is not clear, however, that the convenience of the Windows programs is due to Windows per se as much as it is the result of general improvements in statistics programs. These changes have made statistics packages progressively more convenient as they have shifted from mainframe platforms through several DOS or Macintosh generations to the present.

Windows and even more hardware intensive systems are squeezing DOS software out of the marketplace. Therefore to avoid buying a soon-tobe-discontinued product, prospective purchasers of a DOS program may want to inquire whether the company involved intends to continue to improve its DOS merchandise. However, buying into a DOS dead end may not be a mistake if the price is 